\title{
Territory Planning Model Integrating GIS and Supply Chain
}

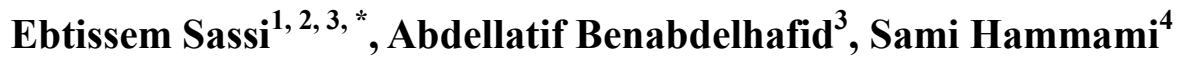 \\ ${ }^{1}$ Department of Transport and Logistics Management, University Institute of Technology of Le Havre, Normandy University, Le Havre, \\ France \\ ${ }^{2}$ Normandy Innovation Management Enterprise Consumption Laboratory, Le Havre University, Normandy University, Le Havre, France \\ ${ }^{3}$ Le Havre Applied Mathematics Laboratory, Le Havre University, Normandy University, Le Havre, France \\ ${ }^{4}$ Research Unit in Development Economics, Faculty of Economics and Management of Sfax, University of Sfax, Sfax, Tunisia
}

Email address:

Ebtissem.sassi@univ-lehavre.fr (E. Sassi)

${ }^{*}$ Corresponding author

\section{To cite this article:}

Ebtissem Sassi, Abdellatif Benabdelhafid, Sami Hammami. Territory Planning Model Integrating GIS and Supply Chain. International Journal of Transportation Engineering and Technology. Vol. 6, No. 1, 2020, pp. 1-15. doi: 10.11648/j.ijtet.20200601.11

Received: November 22, 2019; Accepted: December 7, 2019; Published: January 6, 2020

\begin{abstract}
The territorial redevelopment occupies a very important place in the states because it is not unrelated to their level of development. Also, the redevelopment of territories encompasses several areas: economic, environmental, political, social and logistical. On the other hand, the transport policy is at the crossroads of economic, social, technological and environmental issues. It requires a transversal approach to ensure optimal mobility of citizens and goods. Because of the growth of freight traffic, we are interested in the exchange of physical flows in the hinterlands. This exploratory study has a fivefold purpose. First, we propose to mention some works based on the development of models of the decisional process and we show the multidisciplinary of the problem of territory planning. Second, we clarify the difference between the different types of Geographic Information Systems (GIS) data. Then, we propose to give a classification by approach for models of territorial decision support systems. Thus, we propose a model to identify the different relationships between the territory, the actors involved in decision-making and the different decisional constraints by integrating logistical constraints. Finally, we suggest a generic approach for the conception and generation of a hybrid model MCA-GIS adopted by all the actors intervening in the process of territorial decision takings, we suggest conceptual modeling of this system and we develop a prototype of our suggested model called LOGIS. By this study, this model meets this issue.
\end{abstract}

Keywords: Complexity, Territory, Logistics, Territory Planning, Decision Support System, Conceptual Model, Geographic Information Systems, Multi-criteria Analysis

\section{Introduction}

As a consequence of pollution and congestion, actors intervening in the territory planning within the framework of the logistic organization of supply chain in the hinterland have various solutions like the construction of new infrastructures, implementation of new logistics buildings, and movement of an already built logistic building. At the same time, actors must respond to different objectives:

1. Preserving the use of the territory.

2. Ensuring the fluidity of transport of goods.

3 . Respecting and restricting the budget etc.

However, each of these solutions has positive and negative consequences regarding these objectives. For example, the construction of a logistic building allows the fluidity of goods transport but it induces costs of construction, maintenance, and use, as well as it can have negative impacts on the environment.

In this article, we are going to deal with a very complex problematic associated with territorial decisions.

This complexity is due to:

1. Multidisciplinary: The intervention of different actors (institutions, etc.), their behavior objectives, differentiation, and their interactions.

2. Multi-objective: Heterogeneity and the big number of the performance indicators of territory planning.

3. Multidimensionality of data: The important data have a quantitative and qualitative nature $[1,8]$. 
Territory definition changes according to the discipline. In mathematics, it is made of an arbitrary number of independent axes. In social science, it is considered as a resource or an interaction framework [2]. Territory distribution between the different users is the target of the planning. It is a complex scientific problematic since the good management of territory can be only ensured through achieving a balance between the different objectives fixed by the different actors intervening in the territory planning. It must go through the combination of actions between the different actors while ensuring the achievement of the different objectives since each one has a specific territory representation and often has a tendency to favor certain objectives over the others.

In every society, information plays an important role in the development and support of policies. Hence, reaching reliable and precise information is essential to the decisional logic [3].

The multidisciplinary of the territory management explains the importance of developing multiple representations of the territory where the importance of the development of a decision support system responds to this Plurality. As a medium of a future reflection on the actions to be committed, the modeling of this system must not be limited just to the spatial factors, we take into consideration other factors and integration actors networks sometimes extremely complex [35].

This article highlights the importance of the integration of various criteria and parameters in the future for sufficient precise territory planning.

The first fundamental objective of this paper is to describe firstly the different works achieved in the framework of the decision support system, following a literature review.

The second primordial objective of this paper is to develop a conceptual model of the territory integrating logistic optimization criteria, functional criteria and geographic parameters. This model offers general modalities of collaborative decisions taking support regarding territory planning. The taken decision has a common nature, it is under the focus of researchers in the human sciences (geography and economy) and in the science of nature (ecology). The main objective is creating a tool that favors reflection and dialogue and encourages the different actors to be gathered around a collective planning project. The originality of this model consists of centralizing the work of formalization on the correlation between territory and logistics and collectively confronting the vision of the different actors in function to many own goals and according to the data basis which is particular.

The objective of this model is to facilitate the balance of the exchanges between different actors around a problematic. However, this balance can be difficult to establish by all the actors simultaneously. Indeed, each actor has often a tendency to favor its objectives at the expense of others. Understanding the necessity to reach a balance is then an important issue for all the actors.

Within this framework, we fix as objective the design and achievement of a model which centralizes multidisciplinary data and serves decision support tool. The suggested architecture and the diverse developed functionalities make the achieved tool a different system to the other existing systems.

This paper is structured around five parts that help us to answer the following questions:

1. What are the different decision levels in a territorial system?

2. What are the intervening actors in spatial planning?

3. What is GIS? And what are their classifications?

4. How can we model a territorial system by integrating logistics?

5. What are the principal approaches from which we are going to rely on the development of this model? And why?

6 . How does the model work?

7. How to represent the prototype of our model?

\section{Multidisciplinary Study}

Traditional decision support systems oriented to a "sole decision-maker or mono-actor" do not represent reality. Hence, a new trend was born, "collective decision support".

\subsection{The Territorial Decisional Process Model}

Simon teaches that the decision is the "result of a choice and a result of a process of formulation and progressive resolution of a problem by a group of actors within an organization" [4].

Before, we must note that the decision-support never replaces human decision making. It just makes it more reassuring.

The decision-support according to [5] is "bringing information which authorizes the surest appreciation of the possible fields and the most correct anticipation of the susceptible results of projected actions so as running the process could take place around the table rather than in the field".

Whereas "Environment and sustainable development decision-making entail a change towards new forms of governance which one of its essential ingredients is greater involvement of all the actors in the decision-making" [6].

\subsubsection{Review of Literature}

Simon [4] elaborated the most referenced model in the field of decision support. It is based on three stages:

Intelligence (knowledge) of the decisional problem: limiting the problem through a clear representation of the object of the study and defining the issues.

1. Analysis: the definition of criteria, the possible actions and the evaluation of solutions.

2. Choice: the selection of the optimal solution to meet the performance criteria.

3. For example, the $\mathrm{Ph}$. D. work of [7], of which, the objective was the elaboration of a methodology that is characterized by the addition of two steps:

4. A step between the analysis and the choice: In this step, we identify all the realistic steps meeting the objectives 
and study all the feasible actions. This step limits the study fields.

5. The second step is by the end of the process: this step is associated to the choice achievement and consolidation. It is a post-evaluation step; it corresponds to the establishment of schedule, means of intervention coordination to ensure achieving the objectives.

\subsubsection{Territorial Planning Instruments}

The review of literature allows us to distinguish three types of instruments used in the framework of urban and spatial planning according to the decisional level where each one corresponds to a decision and a specific analysis territory [8-9]. Figure 1 shows these three decisional levels. For clarity, we are studying this problem in the different decision-making levels:

1. The strategic level: it concerns long-term planning.

2. The tactical level: it concerns medium-term planning.

3. The operational level: it concerns short-term planning.

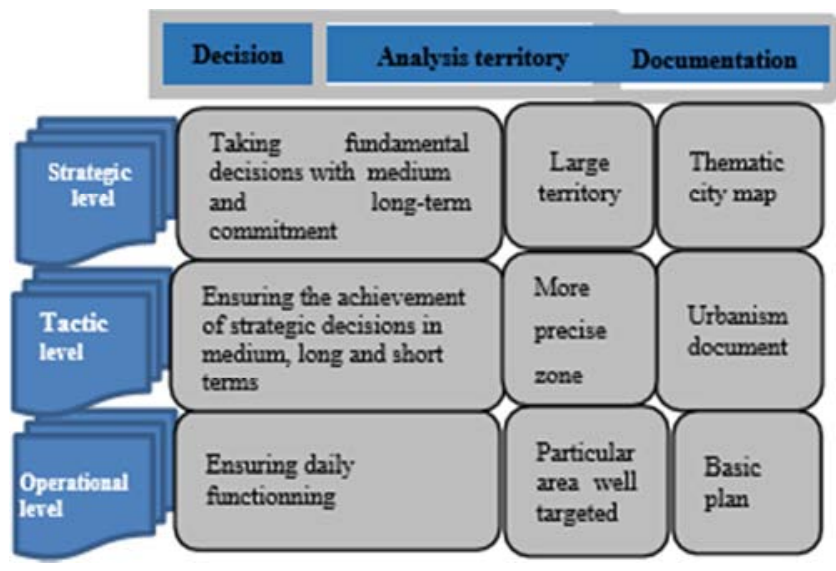

Figure 1. Decisional levels at the level of territory.

Territory planning instruments can be classified according to the spatial level. Names of these instruments change from one country to another. For example, French territory planning instruments are:

1. MP": In 1983, the expression "Master plan of urban planning" was replaced by "Master plan". It was defined by as "an instrument of spatial planning and urban management setting the fundamental orientations of the territory planning of the involved municipalities.

2. SMS ${ }^{2}$ : Sustainable planning and development of territory at the regional scale.

3. LUP $^{3}$ : It is an important regulatory document at the local level, especially on the municipal or even inter-municipal scale which regulates space occupation on a given territory [10-11].

But the problems of these tools are:

1. Insufficient review as a result of the absence of any possible permanent follow-up and rigorous evaluation

\footnotetext{
1 Master plan.

2 Substainable management schema.

3 Local urban plan.
}

of the space.

2. Data exchange complexity between the different sectors where there is a difficulty in coordination between them.

\subsection{Territory Planning: A Multidisciplinary Study}

The multidisciplinary study aims at locating on the territory simple and rapid to use information, oriented to various actors to facilitate planning support and decision making.

The complexity of the territory system is presented according to its evaluative condition and its difficulty in understanding and analysis.

Simply, the territorial system can be represented as the three sub-systems mentioned below. Figure 2 shows the territorial system sub-systems.

This complex system is made of these three sub-systems:

1. Actors using and managing geographic space.

2. Geographic space made by objects.

3. Representations that are established by referring to this space (map, graph).

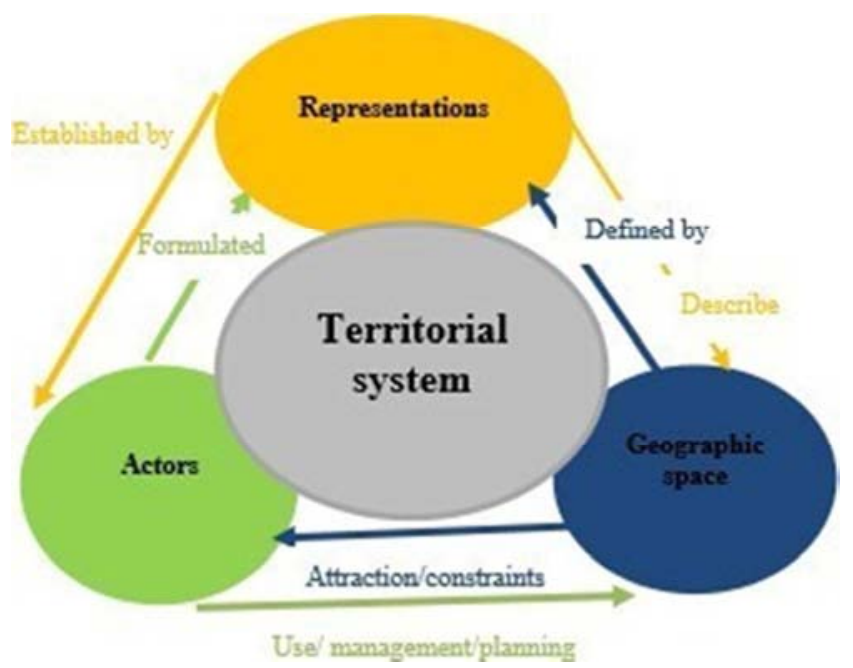

Figure 2. Territorial system sub-systems.

The definition of territory varies according to the disciplines. In mathematics, it is made of an independent arbitrary number of axes. In social sciences, it is considered as a resource or an interaction framework [34]. In environmental science, it is seen as a rare resource that needs maintaining. In geographic science, the territory is described by three dimensions:

1. Structural by taking into account the constituent entities of the territory.

2. Spatial by considering entities and their relationships in space.

3. Temporal by taking account of the historical and the future of entities.

The term territory takes here a meaning given by [11] and represents a restricted territory to the less precise and suitable limits. These five disciplines are located at the crossroads between many requirements imposed by the database of a 
given territory.

Figure 3 shows the different actors intervening in territory planning. Territory planning integrates many actors and requires the consideration of the different field activities: Urbanism, environmentalist, economist, geographer, and politician.

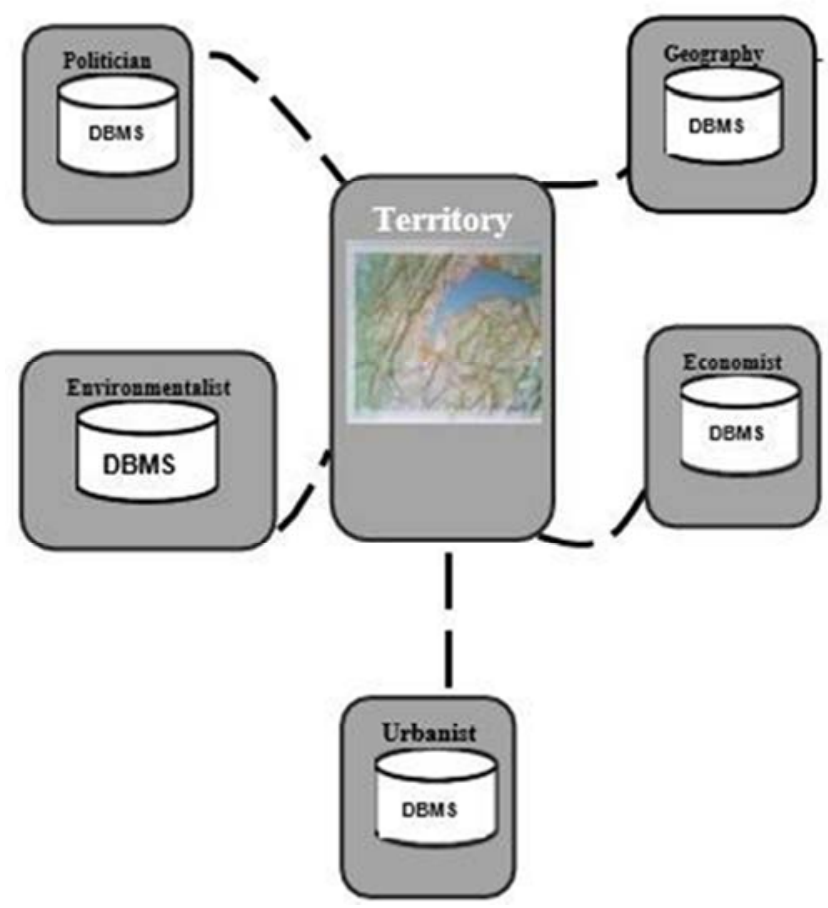

Figure 3. Actors intervening in territory planning.

In the implementation of environmental policy and sustainable development, new regulations and constraints make decision-taking hard. Hence, actors intervening in territory management can face a missing of information.

In this context, the community of geomatics researchers explored new applications of geographic information systems (GIS) as a result of the increase of mobile devices' autonomy, their memory capacity size, and their computing power [12-13].

To ensure the coordination between the different actors, decision-makers (government structure) and planners must have a potential tool for territorial management. This tool is represented as a bank of data and analytical components [14]. In this framework, GIS appears. It is characterized by the combination of an informatics tool and a digital mapping, as part of decision-support information systems.

\section{GIS and Their Classifications}

The GIS are basic tools of research, planning and territorial planning. They aim at making objective decisions that can be understood by non-specialists (elected, etc.). Figure 4 shows the GIS actors. The decision-makers can be classified into three sub-categories:

1. The scientific committee: it combines the computer specialists, the geographers, and the mathematicians.
2. The technical committee: it combines the urbanists.

3. The joined institutions and actors: it combines the elected, the politicians, and the environmentalists.

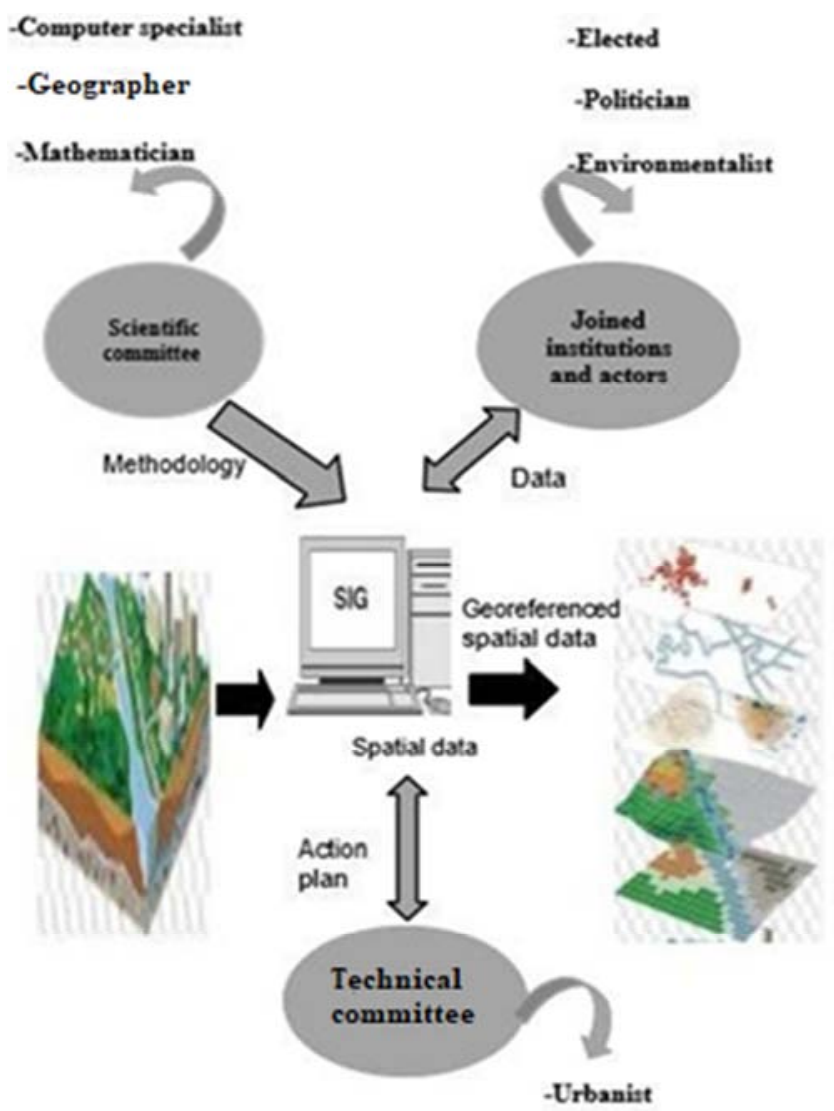

Figure 4. GIS actors.

They are used in different projects of various types (Trans organizational, departmental and personal). They can be applied to different territorial types (local, municipal, supramunicipal, regional, national and international). Their application field is undefined (planning, agriculture, etc.). GIS are used for decision support and spatial understanding of the territory. "The main objective of GIS is taking objective decisions and help no specialist to understand them". Indeed, GIS are mainly used within the framework of mapping thanks to its display feature of spatial data but increasingly as an analytic and territory management tool of planning, modeling decision-taking support, and policies follow-up. GIS have become a field of communication and information technologies used increasingly in the process of decision making, particularly in management and planning [15-16].

\subsection{Geographic Information Systems (GIS)}

GIS are defined according to as "systems for gathering, stocking, verifying and restoring spatial data referenced to the land surface". They can be used during the production of integrated information and at multiple scales. According to [17-18], GIS are information systems allowing, from various sources to gather and organize, analyze, and develop; and to 
represent geographically localized information contributing mainly to territory management. Figure 5 shows the components of the GIS. A Geographic Information System is made of five major components:

1. Computer equipment.

2. Software.

3. Multisource data.

4. Human resources (users).

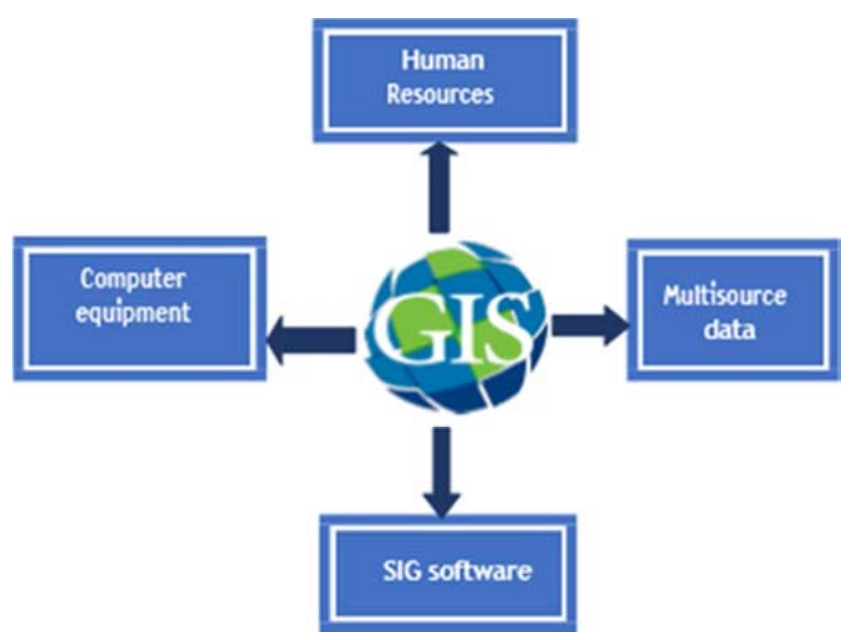

Figure 5. Components of GIS.

The GIS functions are the following:

1. Managing Information: Gathering information of the same type at the same level (layer).

2. Managing databases: Stocking a large amount of multi-source information.

3. Bringing visual dimension to the data: Limiting data in the form of a map.

4. Updating information (dynamic tool).

5. Analyzing data (as a result of generic and spatial criteria).

6. Bringing advanced features: Facilitating data exchange between the different bases and displaying them in the same interface.

They are considered as information systems (IS) allowing the description of the territory to improve its knowledge, as well as the description and the analysis of the natural or human phenomena where they produce. They become indispensable tools in urban management (DGUHC and IGN6). They become like management tools for planning, policy follow-ups, and decision support.

Themes treated by GIS involve:

1. Physical variables (reliefs, etc.).

2. Ecological variables (land use, etc.).

3. Anthropogenic variables (administrative limits, demography, activity, and use, etc.) [18-19].

\subsection{GIS Classification}

GIS can be classified according to their type of use: inventory/observatory, analysis/study, and management/follow-up.

\subsubsection{Decision Support Study}

They can be considered as an analysis support system of the decision. Many decision support applications based on stimulations through connecting GIS to other software were developed. They aim at studying the correlation, as well as analyzing and finding solutions to the different problems and not to a targeted objective. This type of GIS is based on the interrogation function, transformation, and analysis. The structure of the data basis of these systems is developing according to the type of problem to be resolved.

A GIS of this category can be classified according to their decision levels:

1. A long-term decision which is connected to the strategic problem;

2. A mid-term decision concerned with tactic problems and decisions;

3. A short-term decision dealing with operational problems.

Each of these decision types requires a specific type of information.

The table below shows the characteristics of each decision level [20-22].

Table 1. Levels of decisions in the GIS.

\begin{tabular}{llll}
\hline & Strategic & Tactic & Operational \\
\hline Planning Horizon & Long-term & Mid-term & Short-term \\
Results accuracy & Preview & Approximation & Well precise \\
Specialization of the information & Limited scale & Medium scale & Large scale \\
Complexity of the decision & Strong & Medium & Simple \\
\hline
\end{tabular}

Generally, we can observe more exchange and sharing of information between GIS of the same territorial level.

\subsubsection{Inventory-observatory, and Management-follow-up}

The structure of the database of GIS is well defined and fixed to respond to a well-targeted objective. It can be considered as a manipulative tool of geographic information by combining information management techniques and support to the visual representation.

Other than the "study-aid to decision" type, there are two other types of GIS, which are the "inventory-observatory" type and the "management-follow-up" type. The structure of the database of these two types of systems is well defined and not changing to meet a well-targeted objective. They can be viewed as a tool for manipulating geographic information by combining information management techniques with the visual representation. Our work focuses on GIS for study and decision support.

\subsection{GIS Data}

GIS data can be classified according to their natures: 
1. Descriptive data.

2. And graphic data.

\subsubsection{Descriptive Data (Attribute)}

Attribute data provide information that characterizes the geographic data. These attributes can be numeric (number of inhabitants, etc.), date (date of implantation, etc.), and text (name of the municipality).

\subsubsection{Graphic Data (Geometric)}

Geometric data describes the form and position of geographic data. They are represented by points (city, etc.), lines (roads, etc.) or surfaces (agricultural zone, etc.).

\subsection{GIS Choice Issue}

These GIS play an important role in sustainable planning through the acquisition functions and the treatment of geographic information.

They represent the basis of the territorial management because of their ability in:

1. Storage and easy update of multisource data (network data, mapping, etc.).

2. History follow-up of the interventions on this heritage (projects and works linked to territory planning) study and the decision support.

3. Linking data between all the actors.

Inter-sectoral coordination actions on the same space can lead to inter-collaboration at the level of GIS.

The collaboration can be classified in terms of four levels:

1. Communication: Exchange of information between independent systems.

2. Coordination: Non-automatic exchange and file communication.

3. Cooperation: This situation is presented through distance and automatic access to another system.

4. Collaboration: Sharing methods, data and analysis tools between the different organisms may lead to collaboration between the different actors to reach common objectives.

Indeed, GIS have some deficiencies. They "are just a component of the device" [19]. They cannot operate in some situations like the treatment of a scientific problem.

\section{Examples of Projects and Studies on the Collective Territory Planning}

\subsection{The Projects}

The literature offers a few examples of the projects of collective territory planning.

We outline two great international initiatives for the collaborative decisions taking:

1. The first initiative is the example of the territory information systems of the Swiss canton.

2. The second initiative is the cooperative infrastructure knowledge of Canadian territory.
The two projects previously mentioned share important similarities in their objectives: In France, the cooperative spirit between the different intervening actors (networks operators, local collectivities, public services) in the same territory are still rare [23], contrary to Switzerland and Quebec where we find many important initiatives concerning the elaboration of multidisciplinary and multi-objective information systems on a territorial basis.

\subsubsection{The Swiss Example (Territory Information Systems of Swiss Cantons)}

It is based on the coordination and sharing of territorial data among many actors (confederation, cantonal administration, municipalities, distribution enterprises, and study society and research structures. This TIS $^{4}$ is a platform of collection and update of accessible information by all the partners with management and exploitation tools of geographic information [24].

\subsubsection{The Canadian Example (a Cooperative Infrastructure of Territory Knowledge)}

In the framework of the Canadian research project, a multi-source and multi-actor database was developed. The target objective is to achieve a common spatial database available to all the intervening actors and targeting the elaboration of many electronic atlases for the great public use. This platform was the basis of multi-objective and multidisciplinary information and management systems used for territorial planning [23].

\subsection{The Studies: Plurality of Approaches}

This part aims at presenting and comparing the different modeling approaches of decision support systems based on geographic data. Various researches in the field of conceptual models were provided.

Five great approaches stand out. The first is based on a systematic formalization, the second on agents, the third on the artificial intelligence, the fourth on a cellular machine, and the fifth on the multi-criteria approach.

\subsubsection{Systematic Approach}

The systematic approach allows the different actors to rapidly access to information based on recent data and to update the spatial information to ensure decision-taking sharing.

The systematic approach represents, for [25], the ultimate method of use in the field of research dealing with spatial analysis and GIS.

Four sequential steps define the systematic approach:

1. Data production,

2. Information construction,

3. Knowledge elaboration,

4. Results communication.

The systemic approach provides an advantage which is the possibility of gathering multidisciplinary actors in the same structure.

4 Territorial information system. 
According to [26], making a diagnosis to the territory according to the systematic approach must be based on the importance of relationships and interactions between actors, issues of each actor, as well as the constraints.

Following the consultation of different achieved works within the framework of the development of the territory planning plan, we can name a recent study carried out by [27]. The objective of this work is the creation of a master plan of interactive and intelligent urban planning based on complete digital data.

This study is based on a systematic approach that is presented in this process in figure 6. After the analysis of the existing, the plans are geographically normalized, the attribute and geometric data are classed in a CDM (conceptual data model). The last step aims to integrate geographic data.

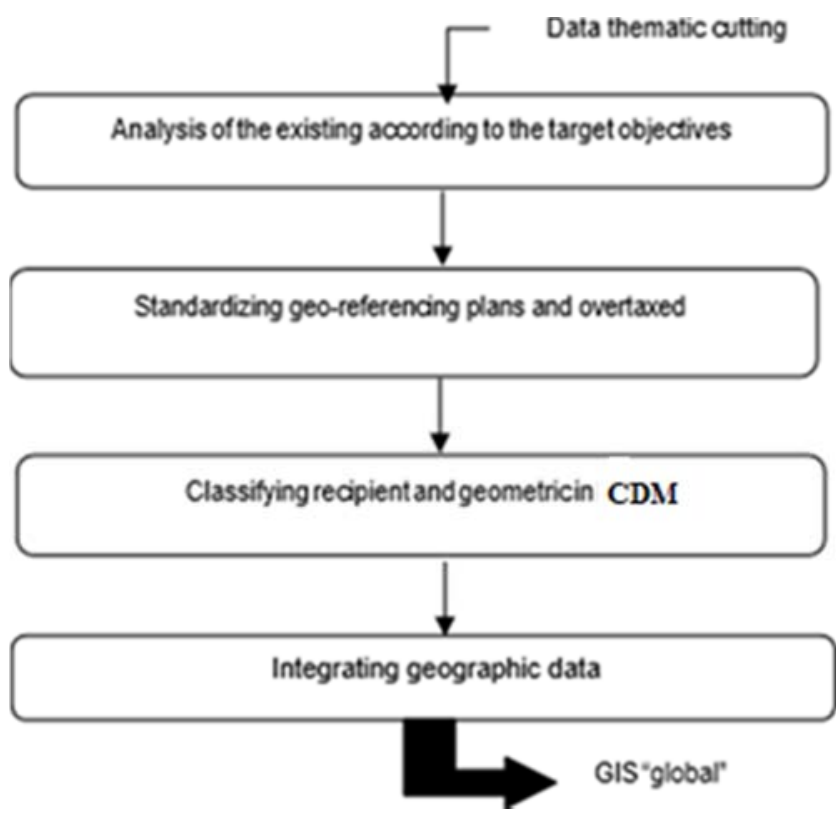

Figure 6. Mapping process of systematic approach for a more general GIS according to Akakba, established by us.

The doctoral work of [28] is founded on the development of a method based on a systematic approach named "systematic representation of the territory". It represents a common framework of reference and normalization. SRT6 takes the form of a hierarchic thematic structure which is based on six levels of abstraction, which are fields (infrastructure, setting, and activity), sectors (transport and natural resources), activities/elements (communication channels), themes (roads), classes (trunk roads) and entities (section).

" $\mathrm{SRT}^{5}$ is seeking the geographic information in a given reference framework as communication support between the different actors-partner" [18].

The territory is described according to three dimensions:

1. Structural through taking into consideration constituent entities of the territory.

5 Systemic representation of the territory.
2. Spatial through taking into consideration entities and their relations in the space.

3. Temporal based on the history and the future of entities.

The latter suggested a territory modeling through a meta representation of objects allowing the comprehension of geographic space, spatial structures, and spatial processes through the integration in a multidisciplinary conception of the different representations, territory actors and GIS partners.

\subsubsection{Multi-agents Approach}

This approach is a technique based on informatics "agents" and characterized by a capacity of reasoning and exchange.

A recent conception of a multi-participant decisionsupport interactive system was elaborated by [29]. This conception is based on a decisional approach allowing the representation of the different actors, their behavior and their interactions. This decisional model is founded on MAS [1]-GIS coupling represented with a negotiation protocol using a multi- criteria analysis method (ELECTRE III and ELECTRE TRI). It aims at supporting the decision-maker of the territory in the problematic of optimal localization of sanitary sites. The two tools used in this work, GIS and MAS, target the presentation of the territory and take into consideration relevant actors related to the decision-making in the territory planning.

Ferrand suggested in his thesis [30], a coupling approach. It was suggested between infrastructures localization support system and territory management negotiation projects support system.

We also name the doctoral work of [29], where she suggested a GIS-MAS model through using a new negotiation protocol.

\subsubsection{Artificial Intelligent Approach}

Various works presented in this framework. For example, we can mention the works of $[31,33]$.

In the work of [33], a decisional methodology was elaborated. It is based on the combining use of GIS, artificial neurons networks of type "perceptron" multilayer and learning algorithm "back-propagation of gradient". Coupling choice was justified by the specificity of the latter as a mathematic tool allowing a problem-solving optimization.

\subsubsection{Cellular Automata Approach}

Looking at old works, we can cite as an example, the doctoral work of Dubos Paillard. In his thesis, he aims to develop a model of the evolution of the urban space of Rouen during the last fifty years $[47,48]$ proposed a formalization of cellular automata. The proposed model makes it possible to represent, in the form of a mathematical graph, the spatial entities of buildings and the urban transport networks; it also makes it possible to calculate the distance-time between the buildings by the network. More recently, we can mention Sammari's doctoral work, which aims to improve data structures in GIS by developing a hierarchical structure of data. The operation of this prototype has been validated by an experimental study on the experimental basin of the 
Montmorency forest in Quebec [49].

\subsubsection{Multicriteria Approach}

Multi-criteria analysis is often used when dealing with decision problems. It allows taking into account the different criteria defined by the actors when making the decision. It is based on the hierarchy and the weighting of the criteria according to their relative importance concerning the problematic. Various works exist in the literature on spatial planning based on the use of multi-criteria analysis. We can cite in a non-exhaustive way the works of [50-53].

More recently, we find the doctoral work of Prévil. The latter has developed a methodological approach integrating Geographic Information Systems (GIS) tools and a Multi-criteria Decision Analysis (MCDA) method. This approach aims to help to share the preferences of territorial actors to facilitate negotiation and simplify the decision-making process [54]. Finally, we can cite in this context, the doctoral work of Ayadi which aims to develop an application of the multi-criteria approach to decision support [55].

\subsubsection{Object-Oriented Approach}

The object-oriented approach is an object-oriented modeling approach. It allows the conceptual modeling of applications in several domains such as GIS [56].

The objective of the work of [57] is to develop a multi-sources GIS for good management of the urban fabric, good environmental protection of the heritage and good planning of its future development. A generic conceptual approach to GIS has been developed by [23] for the design and generation of Spatio-temporal information systems. The objective of $[44,16]$ is to present a conceptual methodology of a GIS model using UML diagrams.

A recent study was developed by [55] and inspired by the work of [27] on data coding based on a standard international extension for spatial data exchange. This team has developed an open data format CityGML6 for storing and exchanging urban models. This study aims to propose a generic model of a city that can be used later in other studies in different disciplines.

\section{Conceptual Modeling of a Territorial System}

Contrary to the territory planning models suggested in the literature which integrate only geographic parameters and functional criteria, our model is multi-actor integrates the logistic optimization criteria. Our model allows showing the different relations between territory, actors intervening in decision making and the different decisional criteria.

This modeling will then give better visibility of the territorial decision support process.

We use, at this level, mainly the class diagram of UML

6 Geographic mark-up language. language. We will explain later on the different classes which make up our model.

\section{1. "Territory»}

The term "territory" is generic. Indeed, it corresponds to the different observed geographic levels. It's proven that it is necessary to assign to its classes according to the nature of the occupation.

1. Free space which corresponds to a non-covered part of the territory.

2. Occupied space which corresponds to a covered part of the territory.

\section{2. «Actors»}

The decision cannot be made without the interaction between all the following actors: geography, politician, environmentalist, urbanist, and economist.

1. Geographer is an entity that intervenes as a consultant, alongside decision-makers of territorial collectivities.

2. Politician is an entity which in search of a better human repartition and economic fairness, in function to resources.

3. Urbanist is an entity intervening upstream and downstream of the project. It collects and interprets data and participates in the process of decision and to the policies of planning.

4. Economist is an entity responsible in the promotion of executing regional sources and improving the life framework and existence conditions of the inhabitants.

5. Environmentalist is an entity which mainly aims at protecting a setting or space.

\section{3. "Resource»}

These resources are important for the achievement of a territory planning decision. We distinguish four types of resources:

1. Software resources.

2. Financial resources.

3. Material resources.

4. Human resources.

\section{4. "Urban Infrastructure»}

In this framework, we distinguish two types of urban infrastructure:

The first one is the "transport infrastructure" made of transport networks (road and railway) and "ancillary infrastructure" for example, the sidewalk, etc.

Secondly, the "ancillary circulation zone" representing zones no targeted by traffic like green spaces along the ways.

\section{5. "Logistic Actor»}

We consider a logistic chain made of the following links: Supplier, production-company, customer and logistics building.

1. Supplier: It is an entity that supplies the enterprise by 
raw material or any components needed in the manufacturing of the product.

2. Production-company: It is a structure having means and resources for the production of goods.

3. Customer: It is the entity to whom the product is oriented.

4. Warehouse: It is where goods are stored for the sake of reshipping. They made the object of subcontracting of a logistic provider or managed by the enterprise.

\section{6. «Project»}

In this framework, we distinguish two types of projects:

The first one is the "logistic building" allowing the supply of many "logistic actors" (supplier, production company, customer, and warehouse) where we distinguish the following types):

1. The warehouse where the storage time surpasses 24 hours.

2. Logistic platforms characterized by storage time for less than 24 hours.

The second one is «urban infrastructure".

\section{7. "Constraint»}

The territorial system must meet the constraints related to territory planning. A constraint can have a geographic, operational nature and of a logistic optimization.
1. Logistic optimization constraint: Can be relative to cost, quality, and deadline.

2. Geographic constraint: has a spatial type.

3. Functional constraint: relates to the constraints imposed by the terms of reference.

\section{8. "Geo-referenced map»"}

It is a data representation medium relative to a territory developed by a GIS.

\section{9. "Decision"}

We consider that each decision is made in the framework of the project. Every decision is made by an actor requires resources to be achieved.

\subsection{Global Model}

The territory undergoes decisions that aim at its planning. These decisions are related to a "project" of implantation of urban infrastructure and logistic buildings. These logistic buildings serve to supply logistic actors from the port and vice versa. The decision is made by an "actor". The territory is submitted to impose constraints either by actors or by the decision. Figure 7 shows our proposed territory planning model. Our model is centered on "territory". It shows the correlation between the "actors". "Logistics actor" and the "constraints".

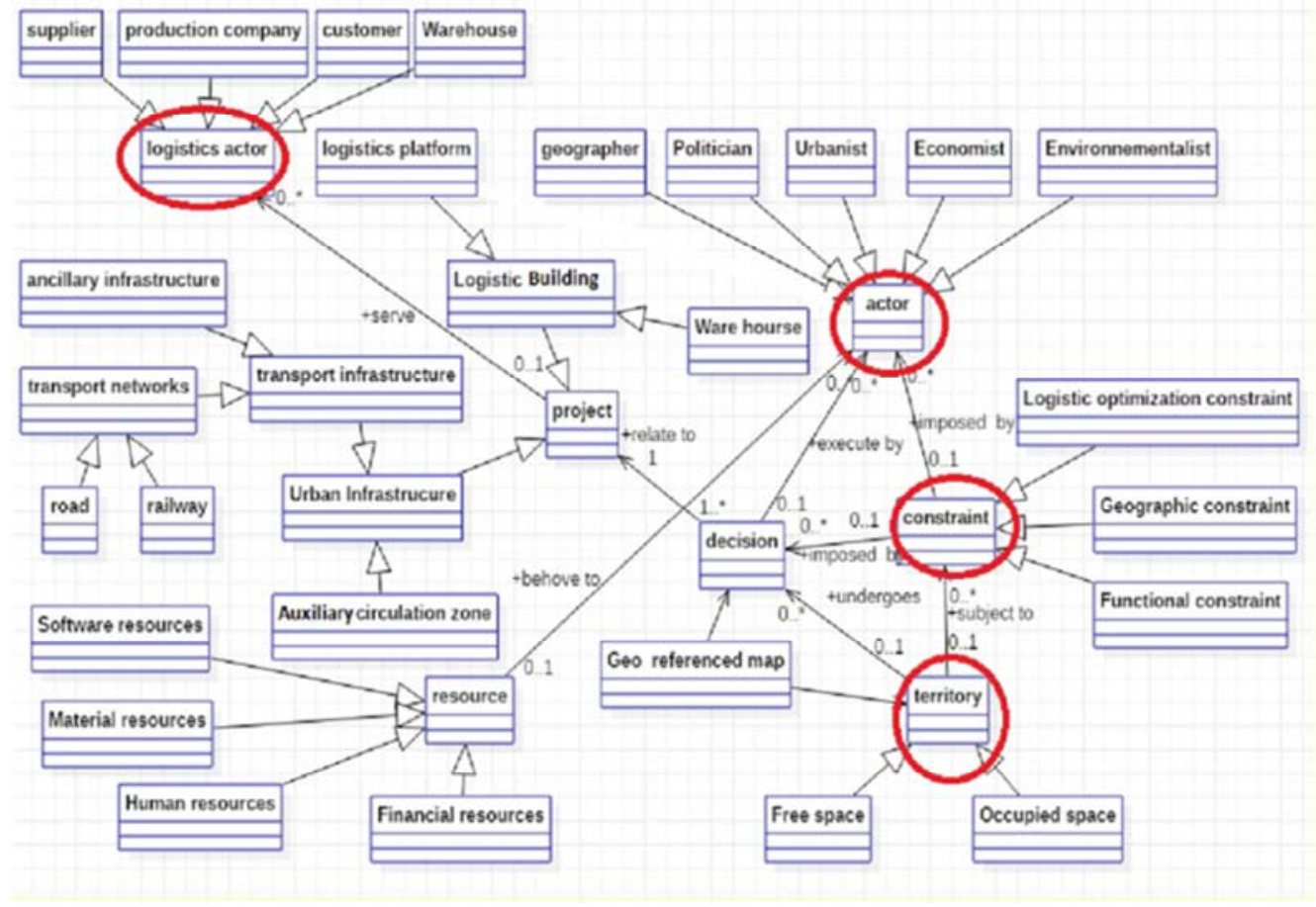

Figure 7. A Proposed Territory planning model integrating actors and criteria of logistic optimization.

\section{The SIAD: A Hybrid Model GIS-MCA}

To help territorial collectivities in the territorial decision making, we adopt an approach of multi-criteria analysis of multisource data. We will take into consideration two parallel phenomena. Indeed, we develop a model based on the coupling between the multi-criteria analysis and GIS to improve the performance of our system and to better handle this rare heritage. Figure 8 shows the approach and tool used in our model. Our model is based on a collaborative participative multicriteria approach and a geomatics tool. 


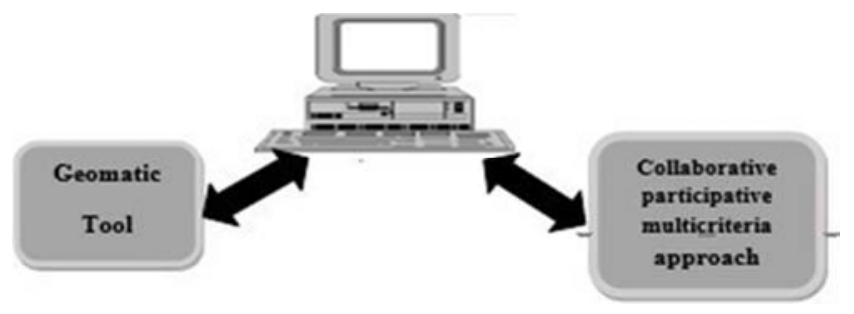

Figure 8. Approach and tool used in our model.

\subsection{DSS: Towards an IDSS}

The term DSS was introduced by the Anglo-Saxon school under the term of "Decision support system". Research on IDSS exists for about thirty years [35]. Works on the axis of research cover a large number of applications. IDSS is an "information system automatized, interactive, flexible, adaptable and specifically developed to help the resolve of a decision not structured and improve the decision making. It uses data, provides a simple user interface and authorizes the users to develop their ideas." [36]. the three fundamental components of an IDSS are:

1. The interface man-machine: It's an interface where the user is related to the system components.

2. Data basis management system (DBMS): It allows the addition, organization, record, and suppression of data.

3. The basis management system of the model (BMSM): it gathers models and procedures of calculation available to the user and used in the different standard treatment of data [37].

Another recent structure more general of an IDSS was developed by Marakas. It is characterized in comparison to other classical information systems by the addition of a complementary part different to DBMS and BMSM. It is based on:

1. Knowledge basis management System (KBMS): It gathers relative tasks to the recognition of the problems, to the generation of solutions and the functions relative to the management of the process of problems resolving.

2. The user interface: It allows access to data, the use of calculation and the communication of results.

3. The user: It is a part of the process of problem resolving [38].

Figure 9 shows the structure of a SIAD according to [37-38], developed by us.

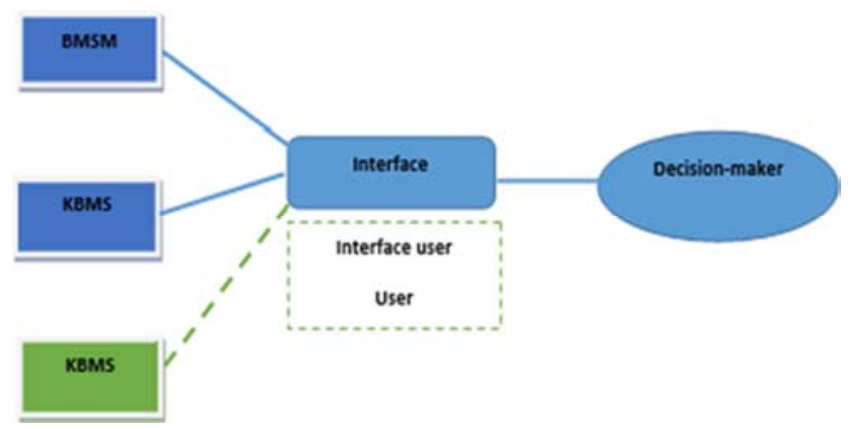

Figure 9. Structure of a SIAD according to [Spragueet, 1982] and [Marakas, 2003], developed by us.
Decision support is a wide field. It includes diverse methods like operational research, simulation, etc. The method chosen depends on the problem to be solved.

We must make a distinction between two types of decision support methods [39].

1. A method of continuing decision support: consists of finding input values that optimize output value by respecting explicit constraints. For example linear planning.

2. A discreet decision support method: consists of finding the best solution (s) among many ones, predefined. The constraints are implicit and are defined by the group of possible solutions.

\subsection{GIS: Towards a Metamodel}

The term metadata was used to refer in a general way to information relative to data.

Often, territorial decision support tools are computerized and connected to a GIS to allow the generation of the complex nature of this common heritage.

With the development of data basis and the orientation towards Metamodels of GISs as well as the amelioration of the tools and models, GISs have become more and more integrated within the process of territory planning. Moreover, "specialized knowledge makes a true data basis, impossible to be made outside such approach" [40].

\subsection{Multi-criteria Analysis of Decision Support}

For the GIS to become a decision support system, its weaknesses will be filled through its coupling with other approaches. Among these approaches, we can mention the multi-criteria analysis.

The multi-criteria analysis is a tool of decision support developed to resolve the complex multidimensional problems including non-measurable dimensions [41]. Hamdadou defined the MCDA as "It is considered as one of the most important branches of the operational research and decision theories. It is exploited to provide approach and solutions tools for complex decisional problems at the same time" [42].

Four reference issues can be mentioned, namely:

1. Storing issue.

2. Triage issue.

3. Choice issue.

4. Description issue.

In the literature, we find an important list of multi-criteria analysis methods.

We mention the most important models according to their type of aggregation in the table below.

Aggregation is the fact of synthesizing a quantity of information to minimize the number of problem dimensions.

The table bellows the classification of principal methods of Multi-criteria analysis by type of aggregation. 
Table 2. Classification of principal methods of multi-criteria analysis by type of aggregation.

\begin{tabular}{ll}
\hline Classification & Multi-criteria Methods Analysis \\
\hline \multirow{3}{*}{ Complete aggregation } & MAUT (Multi Attribute Utility Theory) \\
& UTA (Utility Theory Additive) \\
& HAP (Hierarchy Analysis of Processes), etc. \\
Partial Aggregation & ELCTRE (elimination and choice reflecting reality). \\
& PROMETHEE (preference ranking organization method for enrichment evaluations). \\
Local aggregation & MLP (Multi-criteria linear programming) \\
\hline
\end{tabular}

\subsection{Suggested Decisional Model}

A decision support system must be "simple, robust, easy to control, adaptable, and easy in the plan of communication" [43].

In this framework, we mention doctoral works of [44-46] which are based on the development of a fusion application of GISs tools and an MCDA method to simplify the decisional process. The issue of multiplicity of multisource geographic data and the multi-disciplinarily of actors intervening in the territory planning was resolved through the coupling GIS-MCA. The coupled use of MCA and geographic information systems (GIS) can be beneficial for the treatment of our problematic.

To succeed in the development of a reliable model that operates as an efficient tool of decision support, we must take into consideration the multidisciplinary approaches. Our choice of the MCA model is related to the ability to consider the conflictual criteria in and interrelations.

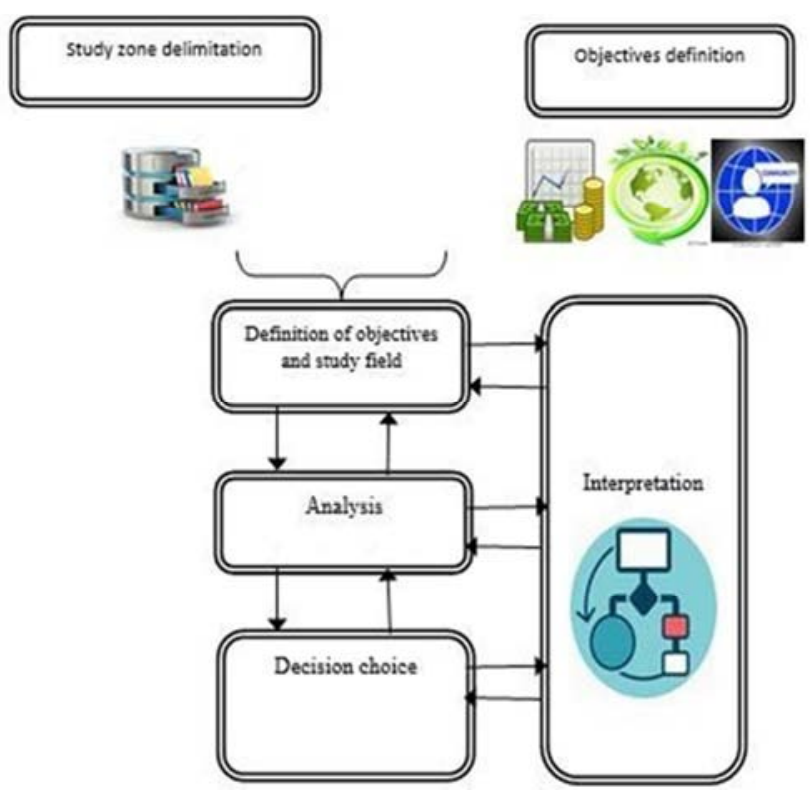

Figure 10. Structure of a suggested decisional model.

We will suggest an approach to the development of collective decision support tools. The suggested model is based on the following procedure:

1. Analysis: definition of criteria.

2. Choice: the selection of possible solutions.

3. Modeling: It is based on the connexion of GIS to the multi-criteria analysis tools.
4. Evaluation: evaluation of possible solutions.

Our model is based on exchanging negotiations between various entities to reach a common decision. Figure 10 shows the structure of the suggested decisional model. After the study zone delimitation and the definition of objectives, the next step aims to analyze the data to choose the best decision.

Our model is based on multidisciplinary approaches. It suggests combining diverse data which present heterogeneity mainly on granularity material. Figure 11 shows the architecture of the proposed decisional model. Our model is based on two approaches:

1. MCA module: for the classification of possible solutions.

2. GIS module: for data georeferencing.

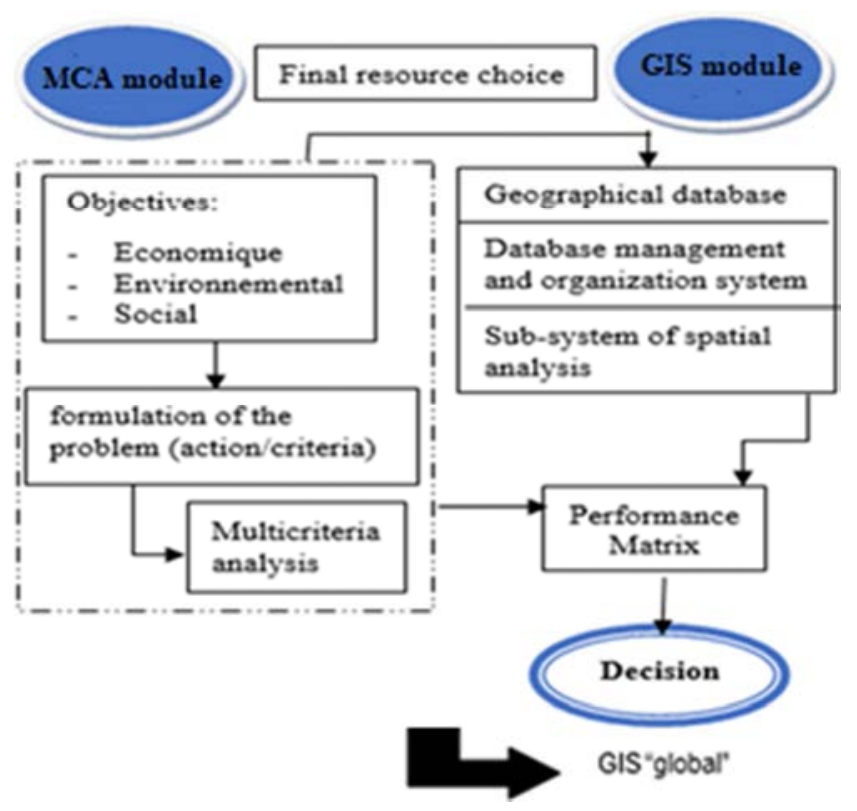

Figure 11. The architecture of the proposed decisional model.

\subsubsection{MCA Model}

The multi-criteria approach was chosen to classify solutions according to the priority order. The Multi-criteria analysis approach is the following:

1. Structuring the multi-criteria decisional model (A, K, E): This step aims to identify the problem through the identification of basic elements of the decisional system:

1) Actions to be executed or possible solutions.

$$
A=\{1,2 \ldots m\}
$$

2) Quantitative and qualitative criteria to be taken into 
consideration during the comparison of actions.

$$
\mathrm{K}=\{1,2 \ldots \mathrm{n}\}
$$

3) Evaluations of actions according to criteria (performance matrix).

$$
E=\{e i j ; \mathrm{i}=1,2 \ldots, \mathrm{m} ; \mathrm{j}=1,2 \ldots \mathrm{n}\}
$$

2. Introducing other modeling elements of the decision-maker preferences:

1) Importance coefficient (weight).

2) The threshold of indifference and preference (S).

Multi-criteria aggregation: to aggregate input "indicators aggregation». The importance of this step is justified when the number of dimensions is important and when we want to establish a global and simplified vision.

\subsubsection{GIS Module}

This integration aims at completing the current evaluation methods by tools facilitating the representation of complex information.

It is important to add precision to the GIS coupling finality: Indeed, our choice of GIS goes to the possibility of the use of data extracted from GIS and brings a visual dimension to the results.

\section{Model Conceptual Modeling and Prototype}

The notions and concepts developed in the previous section constitute the basis of the functioning of our system.

The objective of this part is the conception of a first support model of a multidisciplinary decision system called LOGIS allowing better management of the territory and taking the best decision through network data available to actors.

\subsection{Conceptual Model}

We chose to model our SAD, the UML language that gives us an abstract view of the digital model. Figure 12 shows the UML diagram of the proposed model.

The following UML diagram shows the different steps achieved during the execution of the process described below:

1. The user accesses to the platform and insets the geographic identifications of the port (altitude and longitude). He launches the treatment which releases a request of type "research possibility" to the server GIS to identify possible localization sites (action) in the database GIS.

2. The application will then send a request of type "evaluation indicators" to evaluate the performance indicators (criterion) thanks to the analytic characteristics of GIS and the approach MCA. A matrix of performance (action/criterion) will be displayed afterward.

3. The system sends a request for the type "choice sites" to search for the best solution.
The system poster to the user the most compromised site.

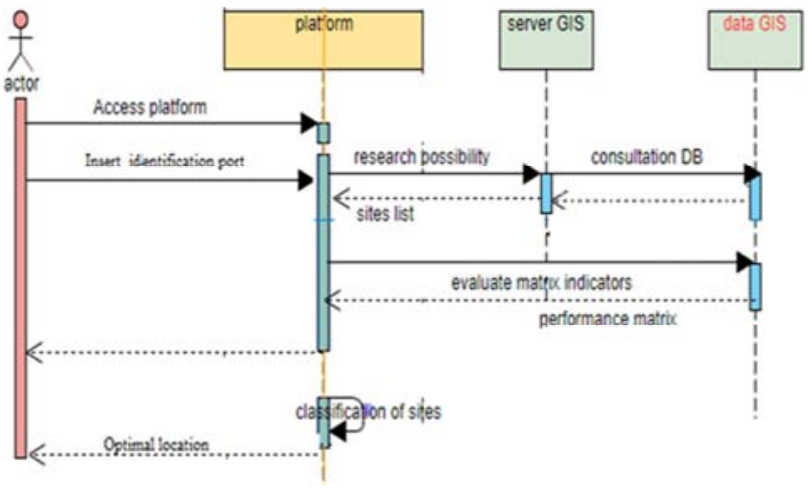

Figure 12. UML diagram of the proposed model.

\subsection{Prototype}

During the achievement of decision-support digital platforms, it is important to go through a preliminary phase to correctly validate the objectives and expectations of the actors. This phase aims at having a global vision of the platform and compensating current challenges that the final product brings.

In this work, the prototype phase is made by the bias of Excel software through the use of macro functions. For this phase, we have prepared various hypotheses. First, we suppose that a free space near to the port eligible for the implantation of logistic building. We divided the territory in an exhausting way based on the method of squaring and we supposed that each square can be a study zone (if the first hypothesis is valid). The second principle hypothesis is that every study zone is off with a transport network. Figure 13 shows the territory squaring.

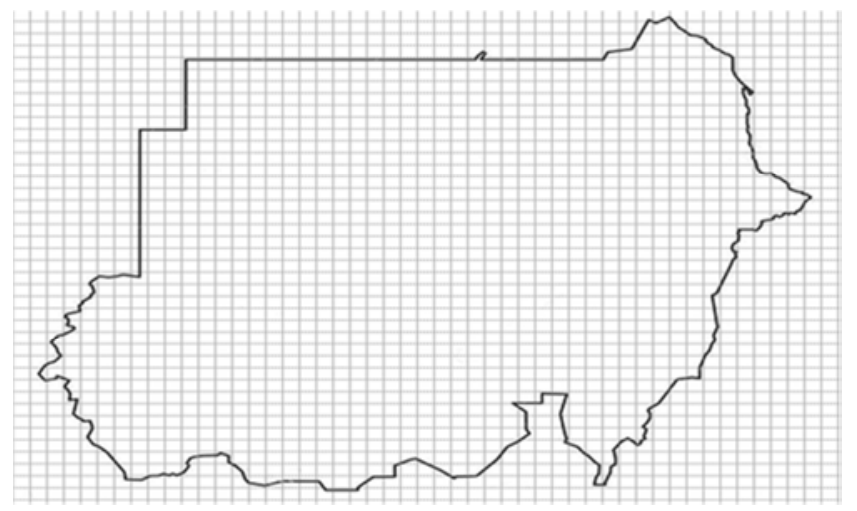

Figure 13. Territory squaring.

Depending on these hypotheses, we have chosen some random criteria. Then, according to the chosen hinterland, the model will suggest to us the favorable zones for the implantation of a zone to the selected port. Figures 14 and 15 below shows the execution of a prototype model. The first interface aims to limit the study area. The second interface allows displaying the optimal and non-optimal location.

In the figure above we can see the result of our research concerning implantation optimal zone. Red zones respond to 
the criteria of implantation possibility but it does not respond to other criteria fixed by the actors. The green zone is a better compromise.

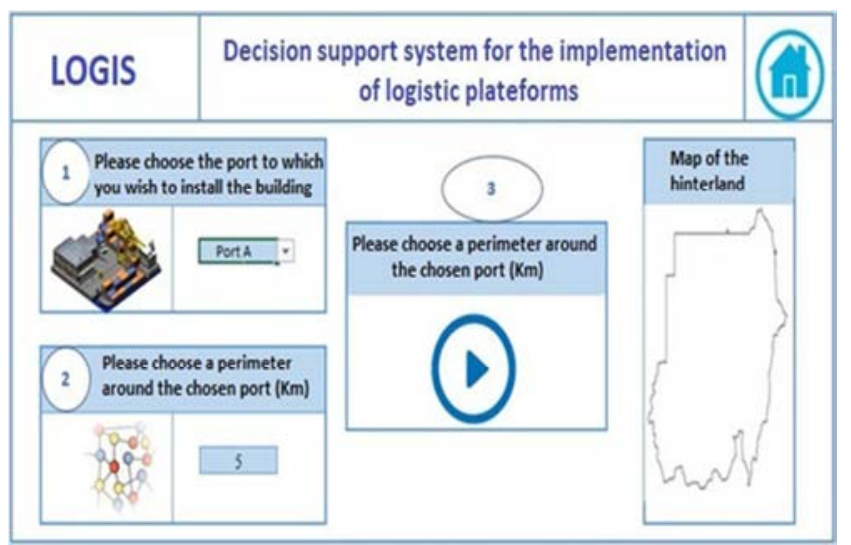

Figure 14. Prototype home-page.

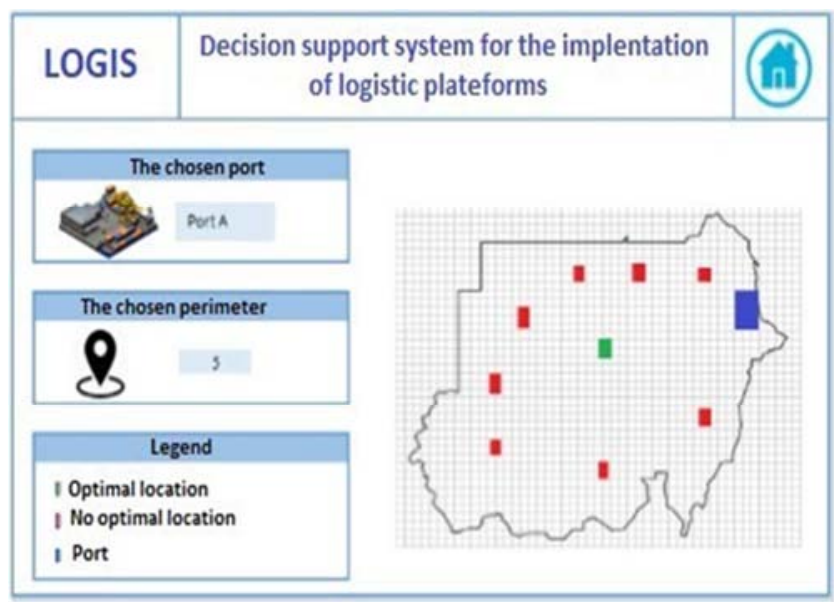

Figure 15. The functioning of the prototype.

\section{Conclusions}

This paper addresses the issue of the multidisciplinary territorial decision-making process. It allowed us to focus on the approaches and tools used in the literature in the context of spatial planning. Admittedly, the list of works cited is not exhaustive, but we tried to present the different approaches dealing with our problematic.

This paper aims at developing a hybrid decisional model based on coupling and Multi-criteria analysis (MCA) with geographic information systems (GIS). This coupling allows the movement from the territorial analysis to the territory planning.

This model has a double advantage: Besides the economic and environmental aspects, the optimal positioning of a logistic platform brings a certain level of service to the actors. The originality of this model lies in focusing the work around the interactions between territory and logistics, and collectively confronting the vision of the different actors towards various specific objectives and according to their particular databases. We have adopted the UML language to model our multi- actors and multi-criteria territory planning model. Indeed, our model is based on collaboration and coordination between the different actors involved in decision-making. We presented a structure of our model, based on various steps: The first phase serves the collection of all data, a second phase aims at a multi-criteria analysis like decision support for the definition of scenarios and the objective of the third phase is, in a global way, the decision making with the best compromise.

The last section of the article aims at contributing to the development of a platform prototype LOGIS to help decision-makers to determine, globally, the best location of a logistic building.

\section{Acknowledgements}

There are many people who contributed, in different ways, to this work, and I would like to take this opportunity to acknowledge them: I would like to extend my appreciation to all my colleagues of Department of Transport and Logistics Management (University Institute of Technology of Le Havre, France). I would like to give a special thanks to Mrs Isabelle ROULAUD, $\mathrm{Mr}$ Olivier BRACAVAL, and $\mathrm{Mr}$ Lionel BRAULT.

\section{References}

[1] Hamdadou, DJ., \& Bouamrane, K. (2016). A spatial group decision support system: Coupling negotiation and multi-criteria approaches. Intelligent Decision Technologies 10 , pp 129-147.

[2] Bucher, B. (2002). L'aide à l'accès à l'information géographique: un environnement de conception coopérative d'utilisations des données géographiques. PhD thesis of the University of Paris 6, p. 207.

[3] Bassolé, A., Brunner, J., \& Tunstall, D. (2001). GIS: Supporting environmental planning and management in West Africa. USA, World Resources Institute.

[4] Simon, H. (1977). Science of Management Decision. New Jersey, Prentice-Hall.

[5] Roy, B. (1975). Combinatorial Programming: Methods and Applications. Reidel Publishing Company, Dordrecht, Holland, NATO Advanced Study Institutes Series. Series C: Mathematical and Physical Sciences, Vol. 19, 459-497.

[6] Van den Hove, S. (2001). Approche participative pour la gouvernance en matière de développement durable: une analyse en termes d'effets. Helbing \& Lichtenhahn, Bâle: Gouvernance I: gouvernance et développement durable, économie et écologie.

[7] Previl, C. (2000). Approche méthodologique pour la préparation de plans d'aménagement axés sur les préoccupations environnementales. Department of Geography. Quebec: faculty of letters -university LAVAL.

[8] Chevalier, J. (1990). Implantation d'un SIRS en milieu municipal: problème d'informatisation ou problème d'organisation. La géomatique, voir... à sa mesure. Montréal: Association de géomatique municipale du Québec. 
[9] Laverdiere, F. (2001). Indicateurs de développement durable et zones d'activités. Comité d'Expansion de la Loire-APD (p. 15). Saint Etienne et école des mines.

[10] Akakba, A., KALLA, M., DRIDI, H., \& FILLALI, A. (2014). modélisation du plan d'urbanisme de la ville d'el Eulma (Algérie). apport de l'intelligence territoriale dans la gouvernance urbaine. Géographie 58, (pp. 43-56). Bucureşti.

[11] CCI. (2006). Enjeux d'Aménagement du territoire et d'Infrastructures en région Centre. les chambres de commerce et d'industrie de la région centre.

[12] Zipf, A. (2002). Location aware mobility support for tourists. Trends \& Controversies. In: IEEE Intelligent Systems. Journal. Special Issue on "Intelligent Systems for Tourism". November/December 2002, 57-59.

[13] Anegg, H., Kunczier, H., Michlmaryr, E., Pospischil, G., \& Umlauft, M. (2002). Designing a Location Based UMTS Application. ÖVE-Verbandszeitschrift, Springer.

[14] Nguendo Yongsi, H., \& Bryant, C. (2007). Contribution des SIG à l'analyse du paysage urbain d'une métropole d'Afrique tropicale humide. Canadian journal of regional science, Spring/printemps 2007, 133-154.

[15] Joliveau, T. (2004). Géomatique et gestion environnementale du territoire. Recherches sur un usage géographique des SIG. université de Rouen: Mémoire d'Habilitation à Diriger des Recherches.

[16] Pinheiro, P., Aparicio, M., \& Costa, C. (2014). Adoption of Cloud Computing Systems. In Proceedings of the International Conference on Information Systems and Design of Communication (pp. 127-131). New York, NY, USA.

[17] DoE. (1987). Handling Geographic information. Report to the Secretary of State for the Environment of the Committee of enquiry into the Handling of Geographic information, Chairman Lord Chorley, HMSO. London, 210.

[18] ONEMA, ASTEE, \& AITF. (2016). Gestion patrimoniale des réseaux d'eau potable. Volume II: Optimiser ses pratiques pour un service.

[19] Gourmelon, F, Ritschard, L., Gourmelon, F., Chlous, F., Différencier les représentations spatiales selon leurs statuts, Revue internationale de géomatique, 1-29.

[20] ZEROILI, D. (2010). L'apport de SIG dans la gestion urbaine: Cas de la gestion des espaces verts. Conférence Francophone Esri, SIG 2010, 29\& 30 September 2010.

[21] Kreitner, R. (1992). Management. McGraw- Hill Book Company, 662.

[22] Peters, E. (1994). La gestion intégrée des ressources au Québec, outils méthodologiques et leur application à la réserve faunique Mastigouche. ENGREF Nancy, 75.

[23] Davoine, P., Moisuc, B., Gensel, J., \& Martin, H. (2006). SIHREN: conception de systèmes d'information spatio-temporelle dédiés aux risques naturels. Revue Internationale de géomatique 16 (3-4).

[24] Papazian, k. (2006). Evaluation du Système d'information du territoire genevois. Département de l'Intérieur, de l'Agriculture et de l'Environnement DIAE. Genéve.

[25] Thériault M., Claramunt C., (1999). La représentation du temps et des processus dans les SIG: une nécessité pour la recherche interdisciplinaire. Représentation de l'espace et du temps dans les SIG, Revue internationale de géomatique, 1999, 9, p. 67-99.

[26] Roche, S., \& Kiene, B. (2007). GEOdoc: nouvel outil d'accompagnement du diagnostic de territoire. SAGEO' 2007.

[27] Billen, R., Laplanche, F., Zlatanova, S., \& Emgard, L. (2008). vers la création d'un méta modèle générique de l'information spatiale 3D urbaine. revue X Y Z -114, 37.

[28] Prelaz-Droux, R., (1996), Roland Prélaz- Droux: Système d'information et gestion du territoire. Approche systémique et procédure de réalisation. Revue de Géographie Alpine, 84-2, p. 115 .

[29] Hamdadou, DJ. \& Bouamrane, K. (2007). A Multi-criteria SDSS for the Space Process Control: Towards a Hybrid Approach. Mexican International Conference on Artificial Intelligence (MICAI), 139-149.

[30] Ferrand, N. (1997). Modèles Multi-Agents pour l'aide à la décision et la négociation en aménagement du territoire. Doctoral thesis, University Joseph Fourier, 312.

[31] Sui, D. (1994). GIS and urban studies: positivism, postpositivism, and beyond. Urban geography, 258-278.

[32] Thurston, J. (2002). GIS and artificial neural networks: DOES your GIS think? GIS vision magazine.

[33] Younsi, F., \& Hamdadou, J. (2009). Vers Un Système d'Aide à la Décision en Aménagement du Territoire: SIG, Méthodes Multicritères et Réseaux de Neurones. Conference: International Conference on Computer Science and its Applications.

[34] Sassi, E., Benabdelhafid, A., Hammami, S., Industrial ecosystem of the territory: strategies and perspectives, The 10th IEEE Service Operations and Logistics, and Informatics (SOLI), Hammamet, Tunisie, pp. 216-220, 2015.

[35] Taghezout, N. (2011). conception et développement d'un système multi agent d'aide à la décision pour la gestion de production dynamique. France: doctoral thesis, university of Toulouse.

[36] Turban, E. (1995). Decision Support and Expert Systems. New York, Macmillan.

[37] Sprague, R., \& Carlson, E. (1982). Building Effective Decision Support Systems. Rentice-Hall, Inc, Englewood Cliffs.

[38] Marakas, G. (2003). Decision Support Systems In the 21st Century. Second Edition, Prentice Hall.

[39] Pomerol, J.-C. (1993). Multi criteria DSS: state of the art and problems. 197-212.

[40] Moine, A., \& Faivre, E. (2011). Le territoire comme un système complexe: de la représentation... à l'action. Actes de la Conférence Intercontinentale en intelligence territoriale INTI 2011, Gatineau, Québec, 95-103.

[41] ANIMA. (2014) reférentiel -guide méthodologique. Economic development through inclusive and local empowerment (July 2014).

[42] Zemri, F., \& Hamdadou, D. (2014). Integration of Multi Criteria Analysis Methods to a Spatio Temporal Decision Support System for Epidemiological Monitoring. ICAASE 2014, 116-123. 
[43] Dupont, J., Smitz, J., Rousseau, A., Mailhot, A., \& Gangbazo, G. (1998). Utilisation des outils numériques d'aide à la décision pour la gestion de l'eau. Revue des sciences de l'eau / Journal of Water Science, vol 11, 5-18.

[44] Metral C., B. R.-D. (2010). Ontology-based approaches for improving the interoperability between $3 \mathrm{D}$ urban models. Journal of Information Technology in Construction.

[45] chakhar, S. (2006). cartographie décisionnelle multicritère: formalisation et implémentation informatique. PhD. thesis in Computer Science, University Paris Dauphine, France.

[46] Vazquez Rascon, M. (2013). Développement énergétique par modélisation et intelligence territoriale: un outil de prise de décision participative pour le développement durable des projets éoliens. Thesis, University of Québec at Rimouski, Department of Mathematics, and Computer Engineering.

[47] Dubos-Paillard, E., \& Langlois, P. (2005). modéliser et simuler l'évolution urbaine par automate cellulaire avec parcelle. Colloque international "Fabrique de la ville et mutations des formes d'urbanité", Dec 2005, Oran, Algérie.

[48] Badariotti, D. (2006). Le renouvellement urbain en France: du traitement morphologique à l'intervention sociale. Sciences de l'homme et société- geographie.

[49] Sammari, H. (2014). Développement d'une méthode d'automate cellulaire basé sur une tessellation irrégulière et hiérarchique pour la simulation des processus spatiotemporels. PhD Thesis, Geomatics Research Center, Université Laval.

[50] Brans, J. P., B. Mareschal et Ph. Vincke (1984),
"PROMETHEE: a New Family of Outranking Methods in Multi criteria Analysis", in Ed. J. P. Brans, Operational Research "84, North Holland, pp. 477-49.

[51] Graillot, L. (1998). Emotions et comportement du consommateur. Recherche et Applications en Marketing, 13 (1), 5-24.

[52] Pellier, P. (1999). les éloignées, passages obligés: la civilisation japonaise. L'Île Laboratoire Anne Meistersheim éd., Ajaccio, Editions Alain Piazzola, 301-317.

[53] Farooq, A., Xie, M., Stoilova, S., Ahmad, F., Guo, M., Williams, E. J., Gahlot, V, K., Yan D., and Issa, A, M., Transportation Planning through GIS and Multicriteria Analysis: Case Study of Beijing and XiongAn, Hindawi Journal of Advanced Transportation Volume 2018.

[54] Groger, G. T., Kolbe, T., Czerwinski, A., \& Nagel, C. (2008). OGC city geography markup language (city GML) encoding standard. Open GIS encoding standard.

[55] Ayadi, D. (2010). optimisation multicritère de la fiabilité: application du modèle de goal programming avec les fonctions de satisfactions dans l'industrie de traitement de gaz. doctoral thesis, university of angers-university of Sfax.

[56] Brodeur J., B. Y.-J. (2000). Modelling geospatial application databases using UMLbased repositories aligned with international standards in geomatics. ACMGIS 2000 November 10-11, Washington USA.

[57] GANZETTI-GEMIN, F., BOURGET, E., \& BARRAY, F. (2011). Les paysages en Bretagne. poster de vulgarisation scientifique, commandé et édité par la région de Bretagne. 